\title{
Amelioration and Finite Element Analysis for Oil Groove of a Wet Clutch Friction Disk
}

\author{
Jingang $\mathrm{Liu}^{1,}$, Shaoqing Zheng ${ }^{1, \mathrm{~b}}$, Quan $\mathrm{Li}^{2}$, and Yunshan Zhou ${ }^{2}$ \\ ${ }^{1}$ College of Civil Engineering and Mechanics, XiangTan University, Xiangtan 411105, China \\ ${ }^{2} \mathrm{HNU}$ College of Mechanical and Vehicle Engineering. Changsha 410012, China \\ awellbuild@126.com, bzs2350594@126.com
}

Keywords: Wet Clutch; Convection Heat Transfer Coefficient; Oil Groove Amelioration; Simulation Analysis

\begin{abstract}
The variable relation between oil groove section parameter and convection heat transfer coefficient have been researched at synchronization state under the condition of same flow area. On this basis, three oil grooves have been ameliorated, thermoplastic contact finite element model for the initial friction pairs and the ameliorated ones are created. After the distribution law of stress and thermal of friction pairs are gained, result shows that under the condition of same flow area, ameliorated oil groove can quicken the process of heat exchange, then more gentle temperature and stress gradient are gained, which can provide theoretic reference for wet clutch amelioration.
\end{abstract}

\section{Introduction}

Some oil grooves are made on the friction disks surface for strengthening function of cooling and chip removal. However, it's usually in practical application that friction pairs get overheated, so full analysis for the relation between oil grooves and convection heat transfer coefficient are need imminently. The friction heat isn't uniform distribution during the slip process, which leads to more temperature gradient. Temperature gradient couple with thermal stress, which aggravates no uniform wear between friction pairs, and even leads to local ablation and buckling deformation. Therefore, amelioration oil grooves for gentler temperature gradient should be one of tasks for wet friction clutch structure optimization.

In this paper, the rule that convection heat transfer coefficient vary with the section shape of oil grooves are gained under the condition of same flow area at synchronization stage , based on this, three oil grooves section shape are ameliorated. Subsequently, 3D finite element models of friction pairs are built before and after amelioration, then the distribution rule of temperature field and stress field are gained.

\section{The Convection Heat Transfer Coefficient of Wet Clutch Friction Pairs}

The engagement processes of wet clutch have obvious stage peculiarities, so the form of convection heat transfer are obviously different at each stages too. Usually, the convection heat transfer at end face is simplify as convection heat transfer model cross cylinder surface, and treat heat transfer in oil groove as convection heat transfer in tube.

The calculation of convection heat transfer coefficient for friction pairs at slip stage. Temporality, the convection heat transfer model can be simplified as convection heat transfer model across cylindrical surface. According to different flow states, the cooling fluid is classified as laminar flow and turbulent flow. Flowing across cylindrical surface, the flow state of cool fluid is laminar flow nestled up against wall surface when the Reynolds number lower than $5 \times 10^{5}{ }^{[1,2]}$. The maximum Reynolds number is on outer diameter region during slip process; its specific numerical value is $3.46 \times 10^{5}$, so the flow state of cool fluid is laminar flow during joint face.

Neglecting influence of temperature and pressure to the viscosity of cooling fluid, the convection heat transfer coefficient of laminar flow on friction disk is presented as: 


$$
h_{r}=0.332 \frac{\lambda}{r} R_{e}^{1 / 2} P_{r}^{1 / 3}
$$

Its average value on friction disk is as:

$$
h=\frac{1}{r_{o}-r_{i}} \int_{r_{i}}^{r_{0}} h_{r} d r=0.332 \lambda^{2 / 3} \mu^{1 / 6} C_{P}^{1 / 3} \rho^{1 / 2} \Delta \omega^{1 / 2}
$$

There into, $\mu, \rho$ is the dynamic viscosity and density of cooling fluid respectively, $\mathrm{m}^{2} / \mathrm{s}, \mathrm{kg} / \mathrm{m}^{3}$; $\Delta \omega$ is the relative angle velocity between the friction pairs, $\mathrm{rad} / \mathrm{s} . C_{P}, \lambda$ is the specific heat and heat conductivity of cooling fluid respectively, $\mathrm{J} / \mathrm{g} \cdot{ }^{\circ} \mathrm{C}, 1 \mathrm{KCal} / \mathrm{m} 2 \cdot{ }^{\circ} \mathrm{C} \cdot \mathrm{h}$.

According to the Eq.2, it can come to the conclusion that if without consideration of the variation of physical property of cooling fluid, the convection heat transfer coefficient depends on the relative angle velocity of clutch at slip stage.

The calculation of convection heat transfer coefficient for friction pairs at synchronization stage. It come to the synchronization stage after the slip stage is finished, temporality, there is no more relatively between friction pairs, then localized cooling is done by cooling fluid in oil grooves. Although no heat produce any more, the process of heat exchange should be expedited as soon as possible in case of frequent engagement lead to temperature over $\operatorname{high}^{[3,4]}$. At this stage, the convection heat transfer in grooves can be simplified as convection heat exchange in tube.

At synchronization stage, the convection heat transfer coefficient is presented as :

$$
h=0.023 \lambda(u / v)^{4 / 5} P_{r}^{0.4}\left(u_{f} / u_{w}\right)^{0.11} d_{H}^{-1 / 5}
$$

There into, $\mu_{w}, v$ is the dynamic and kinematics viscosity respectively.

At synchronization state, from formula (3), it can come to the conclusion that the convection heat transfer coefficient of laminar flow depends on factors as follow : The flow state and velocity of cooling fluid in oil groove; The physical properties variation of cooling fluid; The structure parameters $d_{H}$ of oil groove.

\section{Amelioration for Oil Groove section of a Wet Clutch}

The common radial oil groove section of wet clutches is triangle, trapezoid, arc. The structural parameter $d_{H}^{-1}$ of there oil groove types are presented as follow ${ }^{[5,6]}$ :

(1) The structural parameter $d_{H}^{-1}$ of triangle oil groove

$$
d_{H}^{-1}=\sqrt{\tan \frac{\theta}{2}}\left(1+\sin \frac{\theta}{2}\right) /\left(2 A^{\frac{1}{2}} \sin \frac{\theta}{2}\right)
$$

(2) The structural parameter $d_{H}^{-1}$ of trapezoid oil groove

$$
d_{H}^{-1}=\left[\sqrt{\frac{4 A \tan (\theta-90)}{k^{2}-1}}\left(k+1+\frac{k-1}{\sin (\theta-90)}\right)\right] /(4 A)
$$

In the formula (5), $k$ is ratio of up side to down side of trapezoid, allow for the structure of oil groove, $k=1.4$.

(3) The structural parameter $d_{H}^{-1}$ of arc oil groove

$$
d_{H}^{-1}=\left[\sqrt{\frac{360 A}{\pi \theta-180 \sin \theta}}\left(\frac{\pi \theta}{360}+\sin \frac{\theta}{2}\right)\right] /(2 A)
$$

With same size, different groove types and section angle, three friction disks are measured; their specific parameters are obtained. Cool fluid CD40 is adopted, then the convection heat transfer coefficient of turbulent flow is calculated respectively as variation of oil groove section angle $\theta$ at same flow area, as shown in Fig.1. According to Fig.1(a), it is known that the convection heat transfer coefficient decreases gradually as triangle groove section angle $\theta$ vary from $0^{\circ}$ to $60^{\circ}$, however, it increases gradually as groove section angle $\theta$ vary from $60^{\circ}$ to $180^{\circ}, 120^{\circ}$ can be adopted as groove section angle $\theta$ allow for practical facture in order to gain greater convection heat transfer coefficient. According to Fig.1(b), the convection heat transfer coefficient gain the maximum when 
the trapezoid groove section angle $\theta$ is $120^{\circ}$. According to Fig.1(c), the convection heat transfer coefficient decreases as arc groove section angle $\theta$ vary from $0^{\circ}$ to $180^{\circ}, 60^{\circ}$ can be adopted as groove section angle $\theta$ allow for practical facture too.

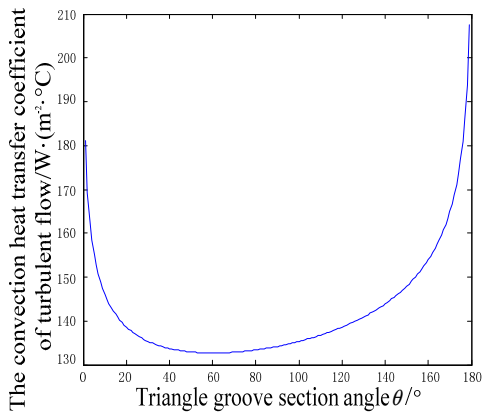

(a) Heat transfer coefficient in triangle groove

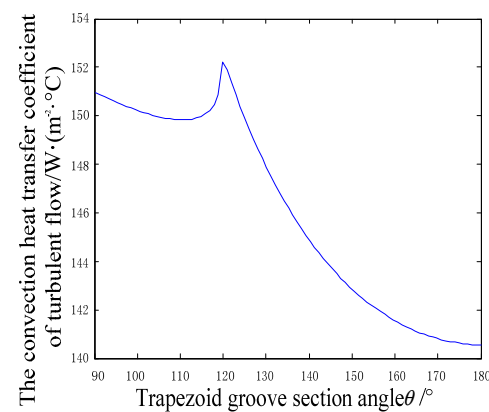

(b) Heat transfer coefficient in trapezoid groove

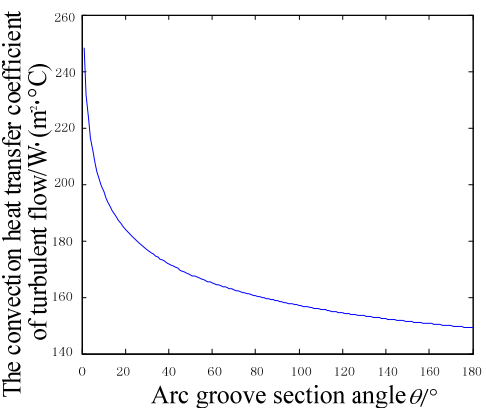

(c) Heat transfer coefficient in arc groove

Fig.1 The Variation of convection heat transfer coefficient in groove of wet clutch

Oil groove width is a significant parameter to wet clutch disk design. Wider Oil grooves mean less reality contact area on the condition of same groove amount and friction surface, which intensify wear process. With full contrast simulation conditions, groove amount should be increased or decreased for same contact area. The structure parameters of oil groove section after amelioration are shown as Table 1.

Table 1 The structure parameters of oil groove section after amelioration

\begin{tabular}{lcccc}
\hline Groove Type Section Angle $\theta /{ }^{\circ}$ & Groove Width/mm & Groove Amount & $\begin{array}{c}\text { Convection Heat Transfer } \\
\text { Coefficient } / \mathrm{w} \cdot\left(\mathrm{m}^{2} \cdot{ }^{\circ} \mathrm{C}\right)^{-1}\end{array}$ \\
\hline Triangle groove & 120 & 5.2 & 28 & 138 \\
Trapezoid groove & 120 & 2.6 & 55 & 151 \\
Arc groove & 60 & 2.5 & 58 & 164 \\
\hline
\end{tabular}

\section{Thermo-mechanical Coupled Contract Simulation Analysis for Friction Pairs}

By dint of ABAQUS, 3D models of friction pairs are built with different groove types and section angle). Half of the real thickness is need, and then they are meshed with tetrahedron thermomechanical coupled unit. Same heat flow boundary conditions are applied on driving and driven disk surface, then convection heat transfer coefficients are applied on corresponding oil groove surface respectively. Both the initial temperature of friction pairs and cool fluid are set at $40^{\circ} \mathrm{C}$. The clutch engagement process can be classified into two load steps: The distance between driving and driven disk is diminished gradually until contact at the first load step; the driving and driven disk began to contact until synchronization at the second load step. The average friction coefficient is 0.09 during slip process, and it needs 2 .3s to finish engagement process. The temperature and stress field are gained after engagement by dint of ABAQUS, as shown in Fig.2.

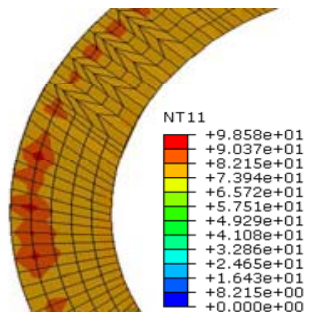

(a) Temperature field

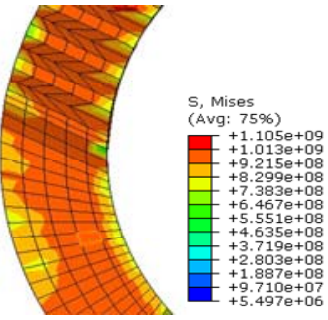

(b) Stress field

Fig.2 The distribution of temperature and stress field on a friction disk

According to Fig.2(a), the general distribution trend of temperature field increase gradually from inner diameter to outer diameter on disk surface, however, the maximum temperature doesn't generate on outer diameter region but the middle region area inner diameter region, moreover, 
ellipse "hot spot" on this region. According to Fig.2(b), stress is higher on middle region, and lower on both outer and inner diameter region, which shows that great coupling relationship exist between temperature and stress field distribution.

Five nodes are picked on friction disks before and after amelioration, the curve of these temperature and stress are plot along disk radial path. According to Fig.3, it can come to the conclusion that the general distribution trend of temperature field are alike: with little influence of convection heat transfer for little temperature difference, little temperature variation occur on inner diameter region; The temperature variation trend of ameliorated groove are milder in varying degrees compare to the ones before amelioration; The maximum temperature occur all on region area outer diameter which is the region that "hot spot" appear frequently. According to Fig.4, triangle and trapezoid groove friction disk bear pressure on their outer and inner diameter region, and that bear pull force on middle region. Outsize axial pressure is the major cause to friction disk warp, although the stress doesn't yet reach the yield limit of material, influence by volatile startup condition, frequent engagement or long-term slip can lead to greater gradient of temperature and stress. Comparing to initial friction disks, axial stress of ameliorated friction disks tend to be milder. With less temperature gradient and more smooth transition structures, arc groove disks get more uniform stress distribution.

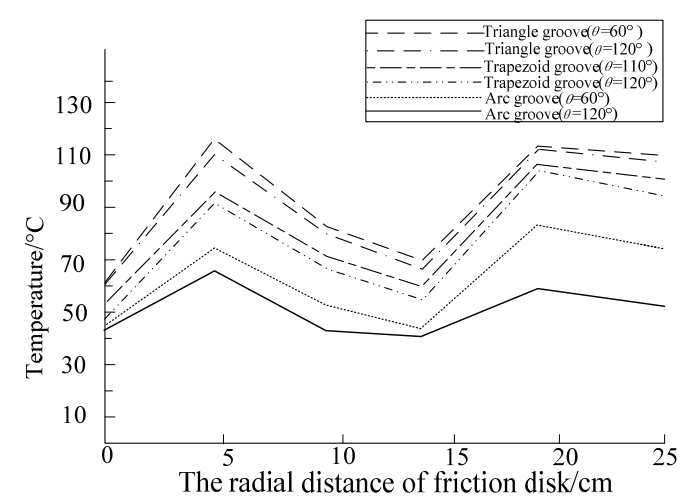

Fig.3 The distribution of radial temperature for friction $\operatorname{disk}(\mathrm{t}=2.3 \mathrm{~s})$

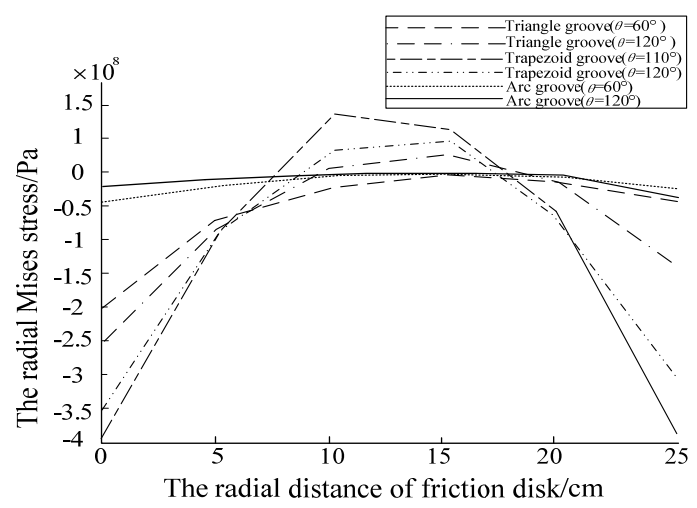

Fig.4 The distribution of radial Mises stress for friction $\operatorname{disk}(\mathrm{t}=2.3 \mathrm{~s})$

\section{Conclusion}

(1) Both flow state of cool fluid and factors effect the convection heat transfer coefficient at different states are discussed in this paper, then the convection heat transfer coefficient of turbulent flow are calculated respectively as variation of oil groove section angle $\theta$ at same flow area, base on which oil groove structure are ameliorated.

(2) The 3D finite element models of friction pairs are built respectively before and after amelioration, the simulation results show: cool fluid have obvious influence on clutch heat emission performance, therefore the heat emission performance of oil groove should be take into account fully; Both the temperature field and stress field are uneven distribution, they affect and coupling with each other; Reasonable amelioration for oil groove structure can mend the distribution of temperature and stress filed.

\section{Acknowledgements}

This work has been supported by the National Natural Science Foundation of China under Grant No. 50905152, and another one under Grant No.51175156.

\section{Reference}


[1]M. Mansouri, M. Holgerson, M. M. Khonsari, et al. Thermal and dynamic characterization of wet clutch engagement with provision for drive torque [J]. Journal of Tribology , $2001,123(2)$ : 313-323.

[2] D. Y. Sun, F. B. Hu, T. Deng. Simulation and experiment for warp characteristic of wet multiple disc clutches[J].Journal of Chongqing University, 2010,30(5):1-6.

[3] K. Okubo, T. Fujii, Y. T. Yasunori. Deformation of pressure plate for manual [C]. SAE Paper, 2005-01-1784.

[4] J. L. Zhang, B. Ma, Y. Zhang. Study on the Factors Affecting Temperature Field and Stress Field of the Wet Shift Clutch[J].Transactions of Beijing Institute of Technology, 2010,30(6):660664.

[5] P. Zagrodzki, K. B. Lab, E. Aibahkali, et al. Nonlinear transient behavior of a sliding system with fictionally excited thermo elastic instability[J]. Journal of Tribology, 2001, 123(4): 699-708.

[6] P. Zagrodzki, S. A. Truncone. Generation of hot spots in a wet multi-disk clutch during short term engagement [J].Wear, 2003, 254 (5) :474- 491. 